\title{
4-Chloro-DL-phenylalanine protects against monocrotaline-induced pulmonary vascular remodeling and lung inflammation
}

\author{
YANG BAI $^{1}$, HAN-MING WANG ${ }^{1,2}$, MING LIU $^{1,3}$, YUN WANG $^{1}$, GUO-CHAO LIAN $^{1}$, \\ XIN-HUA ZHANG ${ }^{1}$, JIAN KANG ${ }^{4}$ and HUAI-LIANG WANG ${ }^{1,4,5}$
}

\author{
${ }^{1}$ Department of Clinical Pharmacology, School of Pharmacy, China Medical University, Shenyang; \\ ${ }^{2}$ Department of Pharmacology, Liaoning Medical college, Jinzhou; ${ }^{3}$ Department of Drug Control, \\ China Criminal Police University, Shenyang; ${ }^{4}$ National Key Subject, Institute of Respiratory Diseases \\ and ${ }^{5}$ Institute of Cardiovascular Diseases, China Medical University, Shenyang, P.R. China
}

Received September 15, 2013; Accepted December 9, 2013

DOI: $10.3892 / \mathrm{ijmm} .2013 .1591$

\begin{abstract}
The present study was performed to investigate the effects of 4-chloro-DL-phenylalanine (PCPA), a tryptophan hydroxylase $(\mathrm{Tph})$ inhibitor (TphI), on pulmonary vascular remodeling and lung inflammation in monocrotaline (MCT)induced pulmonary arterial hypertension $(\mathrm{PAH})$ in rats. Animal models of PAH were established using Sprague-Dawley (SD) rats by a single intraperitoneal injection of MCT $(60 \mathrm{mg} / \mathrm{kg})$. PCPA ( 50 or $100 \mathrm{mg} / \mathrm{kg} / \mathrm{day}$ ) was administered to the rats with PAH. On day 22, hemodynamic measurements and morphological observations of the lung tissues were performed. The levels of Tph-1 and serotonin transporter (SERT) in the lungs were analyzed by immunohistochemistry and western blot analysis. The expression of matrix metalloproteinase (MMP)-2 and MMP-9, tissue inhibitor of metalloproteinase (TIMP)-1 and TIMP-2 and inflammatory cytokines were assayed by western blot analysis. The activity of MMP-2 and MMP-9 was evaluated by gelatin zymography (GZ). MCT markedly promoted $\mathrm{PAH}$, increased the right ventricular hypertrophy index, pulmonary vascular remodeling, lung inflammation and mortality, which was associated with the increased expression of Tph-1, SERT, MMP-2/-9, TIMP-1/-2 and inflammatory cytokines. PCPA markedly attenuated MCT-induced pulmonary vascular remodeling and lung inflammation, inhibited the expression of Tph-1 and SERT and suppressed the expression of MMP-2/-9, TIMP-1/-2, interleukin- $1 \beta$ (IL-1 $\beta$ ), tumor necrosis factor- $\alpha$ (TNF- $\alpha$ ) and intercellular adhesion molecule-1 (ICAM-1). These findings suggest that the amelioration of MCT-induced
\end{abstract}

Correspondence to: Dr Huai-Liang Wang, Department of Clinical Pharmacology, School of Pharmacy, China Medical University, No. 92 2nd North Road, Heping, Shenyang 110001, P.R. China E-mail: hlwang@mail.cmu.edu.cn

Key words: 4-chloro-DL-phenylalanine, monocrotalin, pulmonary arterial hypertension, tryptophan hydroxylase, serotonin transporter, inflammation, remodeling pulmonary vascular remodeling and lung inflammation by PCPA is associated with the downregulation of Tph-1, SERT, MMP/TIMP and inflammatory cytokine expression in rats.

\section{Introduction}

Pulmonary arterial hypertension (PAH) is a complex pathological process, involving pulmonary vascular remodeling and constriction, as well as lung inflammation. It is characterized by a sustained and progressive elevation in pulmonary vascular pressure and the remodeling of the pulmonary vasculature, eventually leading to right ventricular failure and death (1). Vascular active substances, such as serotonin [5-hydroxytryptamine (5-HT)], platelet-derived growth factor (PDGF), interleukin (IL) and endothelin-1 (ET-1), participate in the pathological processs of PAH (2).

The main causes of pulmonary vascular remodeling are hypertrophy and hyperplasia of pulmonary arterial smooth muscle cells (PASMCs), muscularization of normal nonmuscular peripheral arteries and deposition of the extracellular matrix (ECM) (3). The regulation of the ECM is involved in cell growth, proliferation, differentiation and death (4). Matrix metalloproteinases (MMPs), a family of zinc-dependent endopeptidases, play a substaintial role in the degradation of the ECM. In previous studies, we demonstrated that the levels of MMP-2 and MMP-9 in pulmonary arteries are increased in monocrotaline (MCT)-induced PAH models $(3,5)$. MMP proteolytic activity is controlled by specific endogenous inhibitors, which are the tissue inhibitors of metalloproteinases (TIMPs) (6). The increased deposition of matrix proteins in the pulmonary vessels has been attributed to the change in the balance of MMP and TIMP activity (7). Thus, the balance between MMPs and TIMPs seems to be important for ECM regulation and homeostasis (6).

Inflammatory mechanisms appear to play a significant role in pulmonary hypertension (PH), including MCT-induced $\mathrm{PH}$ in rats and PAH of various origins in humans (8). Perivascular inflammatory infiltrates with macrophages and lymphocytes in the areas of occlusive lesions can be observed in PAH $(8,9)$. 
The expression levels of cytokines, such as IL-1 $\beta$, intercellular adhesion molecule-1 (ICAM-1) and tumor necrosis factor- $\alpha$ (TNF- $\alpha$ ), have been shown to be increased in hypoxia- or MCT-induced PAH (3,10-12).

The 5-HT transporter (5-HTT) and serotonin transporter (SERT) play a prominent role in the progression of PAH (13-16). It is known that SERT is involved in pulmonary vascular remodeling and lung inflammation in $\mathrm{PH}$ (17). The mitogenic and comitogenic effects of 5-HT on PASMCs are associated with the cellular internalization of serotonin, which is mediated by SERT $(5,17,18)$. The critical step in 5-HT biosynthesis is catalyzed by the rate-limiting enzyme, tryptophan hydroxylase (Tph) (19). Tph activity, therefore, serves as a marker for 5-HT synthesis (19). There are two isoforms of the Tph enzyme regulating 5-HT synthesis. Tph-1 is mainly present in enterochromaffin cells and spleen, whereas Tph-2 is predominantly present in the brain stem and mesenteric plexus neurons (20). Thus, 5-HT synthesis is thought to be controlled mainly by Tph-2 in the central nervous system and by Tph-1 in the peripheral organs (19). The synthesis of 5-HT and the expression of Tph-1 are increased in the pulmonary vascular endothelium of patients with idiopathic PAH (IPAH) (16).

The inhibition of serotonin by 4-chloro-DL-phenylalanine (PCPA) has been shown to reduce MCT-induced right ventricular hypertrophy in rats (21). However, it is not known whether this Tph inhibitor (TphI) can protect against MCT-induced pulmonary vascular remodeling and lung inflammation. Therefore, in the present study, we aimed to investigate the effects of the TphI, PCPA, on pulmonary vascular remodeling and lung inflammation in rats with MCT-induced PAH.

\section{Materials and methods}

Monocrotaline-induced $P A H$ in rats. Sixty-eight male Sprague-Dawley (SD) rats (weighing $180 \pm 10 \mathrm{~g}$ ) were obtained from the Animal Resource Centre, China Medical University (certificate no. Liaoning 034). The animal care and experimental protocols were in accordance with the Institutional Animal Care and Use Committee of China Medical University. The rats were randomly divided into 4 groups: (i) the control (untreated) group, (ii) the MCT-treated group, (iii) the group treated with $\mathrm{MCT}+50 \mathrm{mg} / \mathrm{kg}$ PCPA $(\mathrm{MCT}+\mathrm{P} 1)$, and (iv) the group treated with MCT $+100 \mathrm{mg} / \mathrm{kg}$ PCPA $(\mathrm{MCT}+\mathrm{P} 2)$. Rats in the MCT and 2 PCPA-treated groups (MCT + P1 and $\mathrm{MCT}+\mathrm{P} 2)$ were administered intraperitoneal injections of MCT (60 mg/kg; Sigma-Aldrich, St. Louis, MO, USA). PCPA (Sigma-Aldrich) was dissolved in physiological (0.9\%) saline. Rats in the PCPA-treated groups were administered intraperitoneal injections of PCPA (50 or $100 \mathrm{mg} / \mathrm{kg}$ ) once a day for 21 days. Rats in the control and MCT groups (MCT alone) received an equal volume of the vehicle $(0.9 \%$ physiological saline) by intraperitoneal injection over the same period of time. All the rats were provided abundant food and water ad libitum. They were kept in a 12 -h light/dark cycle at $18-22^{\circ} \mathrm{C}$ and $50-70 \%$ humidity. The parameters which we measured in the whole experiment were performed in a blinded manner.

Assessment of PAH. On day 22, the rats in all the groups were anaesthetized with $3 \%$ pentobarbital sodium $(40 \mathrm{mg}$ / $\mathrm{kg}$ ). Systemic arterial pressure (SAP) and pulmonary arterial pressure (PAP) were recorded under the same conditions as previously described (22-24). The right carotid artery was isolated and cannulated with a polyethylene catheter to a fluid-filled force transducer. A pressure transducer via the carrier amplifier and multi-channel polygraph was connected. On behalf of the recorded pressure system circulating blood, the SAP was measured. Another polyvinyl PV-1 catheter was introduced into the right jugular vein and pushed through the right ventricle into the pulmonary artery for the measurement of PAP. When the pressure increased and pulmonary arterial waveform baseline appeared, we immediately fixed the PV-1 catheter and began measuring PAP. Prior to catheterization, the catheters were filled with saline containing $1 \%$ heparin. Hemodynamic variables were measured with a pressure transducer and recorded on a polygraph system (RM6000; Nihon Kohden Corp., Tokyo, Japan).

After the measurements were completed, the rats were sacrificed with an overdose of pentobarbital sodium. The heart tissue was separated into the right ventricle (RV) and left ventricle plus septum $(\mathrm{LV}+\mathrm{S})$. The right ventricular index $(\mathrm{RVI})$ was calculated using the following formula: $R V I=R V /(L V+S)$.

Histological examination. The animals were exsanguinated with sterile saline and $4 \%$ paraform. Tissues from the right lower lobe of the lungs were then cut and fixed with $4 \%$ paraform. Subsequently, the paraffin-embedded lung tissues were subjected to sectioning to yield $5-\mu \mathrm{m}$-thick sections and were then stained with haematoxylin and eosin (H\&E). A total of 12 pulmonary arteries were investigated per rat using the MetaMorph (Universal Imaging Corp., West Chester, PA, USA)/DP10/BX51 (Olympus, Tokyo, Japan) imaging system in 3 rats of each group. The pulmonary arteries (external diameter, 60-80 $\mu \mathrm{m}$ ) were randomly selected for high-power (x400) evaluation. Pulmonary vascular remodeling was measured as the percentage of medial thickness, which was calculated according to previously described methods as follows: medial wall thickness $(\%)=($ external diameter - internal diameter $) /$ external diameter) $\times 100 \%(22)$; wall area $(\%)=$ (total vessel area - lumen area)/total vessel area $\mathrm{x} 100 \%(25)$.

Immunohistochemisty. Paraffin-embedded lung tissue sections were stained using ultrasensitive SP and diaminobenzidine (DAB) staining kits (Maxin-Bio, Fuzhou, China). The primary rabbit polyclonal antibody against Tph-1 (BS3727, Bioworld Technology, St. Louis Park, MN, USA) was diluted 1:200, whereas the primary rabbit polyclonal antibody against SERT protein (bs-1893R, Biosynthesis Biotechnology, Beijing, China) was diluted 1:300. As a negative control, samples were incubated with $0.01 \mathrm{M}$ phosphate-buffered saline (PBS) instead of the primary antibody. Digital images were analyzed under a BX51 microscope (Olympus). At least 12 pulmonary arteries (external diameter, 60-80 $\mu \mathrm{m}$ ) per rat were examined in 3 rats from each group. The levels of Tph-1 and SERT protein were calculated as the average optical density. Immunohistochemical staining followed a basic indirect protocol using a citrate antigen-retrieval method $(5,22)$.

Determination of MMP-2/-9 activity by gelatin zymography. The gelatinolytic activity of both the latent and mature forms of MMP-2 and MMP-9 was evaluated by gelatin zymog- 
Table I. Comparison of haemodynamic measurements and right ventricular index between the different groups.

\begin{tabular}{|c|c|c|c|c|}
\hline Parameter & $\begin{array}{l}\text { Control } \\
(n=17)\end{array}$ & $\begin{array}{l}\mathrm{MCT} \\
(\mathrm{n}=9)\end{array}$ & $\begin{array}{c}\mathrm{MCT}+\mathrm{P} 1 \\
(\mathrm{n}=16)\end{array}$ & $\begin{array}{c}\mathrm{MCT}+\mathrm{P} 2 \\
(\mathrm{n}=17)\end{array}$ \\
\hline Body weight (g) & $292 \pm 23$ & $205 \pm 46^{\mathrm{b}}$ & $201 \pm 23^{b}$ & $184 \pm 26^{\mathrm{b}}$ \\
\hline $\mathrm{SAP}(\mathrm{mmHg})$ & $130 \pm 22$ & $120 \pm 24$ & $123 \pm 18$ & $119 \pm 18$ \\
\hline PAP (mmHg) & $14.7 \pm 1.9$ & $25.6 \pm 7.4^{\mathrm{b}}$ & $18.4 \pm 3.5^{\mathrm{a}, \mathrm{c}}$ & $16.9 \pm 4.1^{\mathrm{c}}$ \\
\hline Heart rate (bpm) & $374 \pm 30$ & $393 \pm 19$ & $372 \pm 40$ & $355 \pm 42$ \\
\hline $\mathrm{RV} / \mathrm{LV}+\mathrm{S}(\%)$ & $30.7 \pm 4.2$ & $44.0 \pm 11.3^{\mathrm{b}}$ & $34.3 \pm 3.7^{\mathrm{d}}$ & $32.1 \pm 3.6^{\mathrm{c}}$ \\
\hline
\end{tabular}

Data are expressed as the means $\pm \mathrm{SD}$. ${ }^{\mathrm{a}} \mathrm{P}<0.05,{ }^{\mathrm{b}} \mathrm{P}<0.01$ compared with the control group. ${ }^{\mathrm{c}} \mathrm{P}<0.01$ compared with the MCT group. $\mathrm{SAP}$, systolic arterial pressure; PAP, pulmonary arterial pressure; RV, mass of right ventricle; $\mathrm{LV}+\mathrm{S}$, mass of the left ventricle plus septum; PCPA, 4-chloro-DL-phenylalanine; MCT, monocrotaline; MCT + P1, MCT plus $50 \mathrm{mg} / \mathrm{kg}$ body mass PCPA; MCT + P2, MCT plus $100 \mathrm{mg} / \mathrm{kg}$ body mass PCPA.

raphy. Soluble lung proteins $(40 \mu \mathrm{g})$ were separated on $10 \%$ sodium dodecyl sulphate polyacrylamide gel electrophoresis (SDS-PAGE) containing $1.0 \mathrm{mg} / \mathrm{ml}$ gelatin under non-reducing conditions. Following incubation for $1 \mathrm{~h}$ in washing buffer [50 mM Tris- $\mathrm{HCl}(\mathrm{pH}, 7.5), 2.5 \%$ Triton X-100, $5 \mathrm{mM} \mathrm{CaCl}_{2}$, $\left.1 \mu \mathrm{M} \mathrm{ZnCl}_{2}\right]$ at room temperature, the gels were incubated for $40 \mathrm{~h}$ in incubation buffer $[50 \mathrm{mM}$ Tris- $\mathrm{HCl}(\mathrm{PH}, 7.5), 200 \mathrm{mM}$ $\mathrm{NaCl}, 5 \mathrm{mM} \mathrm{CaCl}_{2}$ ] at $37^{\circ} \mathrm{C}$. The gels were then stained with $0.05 \%$ Coomassie Blue R-250 for $3 \mathrm{~h}$ and destained with destaining solution [methanol:acetic acid:ion-exchanged water (50:10:40)] until bands were visible. Areas of MMP-2/-9 activity appear as clear bands against a dark blue background where the protease has digested the substrate. The strip was subjected to image analysis to determine its gray value, representative of MMP-2/-9 activity. Each experiment was repeated to detect $>3$ batches of different samples.

Western blot analysis. The samples of the left lower lobe of the lungs from the rats in each group were homogenized to extract the protein using a polytron homogenizer (Kinematica, Lucerne, Switzerland). The homogenate was centrifuged at $15,000 \mathrm{x}$ g for $20 \mathrm{~min}$ at $4^{\circ} \mathrm{C}$ and the supernatant was collected and stored at $-70^{\circ} \mathrm{C}$ until analysis. Equal amounts of protein were separated through a reducing SDS-PAGE and electrotransferred onto a polyvinylidene difluoride (PVDF) membrane. Following incubation in blocking buffer $(5 \%$ non-fat dry milk, TBS and $0.05 \%$ Tween-20) at room temperature for $2 \mathrm{~h}$, the membranes were incubated with primary antibodies overnight at $4^{\circ} \mathrm{C}$. Rabbit polyclonal anti-SERT antibody (bs-1893R, 1:300) was purchased from Biosynthesis Biotechnology. Rabbit polyclonal anti-Tph-1 antibody (BS3727, $1: 800)$ and rabbit polyclonal anti-IL-1 $\beta$ antibody (BS3506, 1:700) were purchased from Bioworld Technology. Mouse monoclonal anti-MMP-2 antibody (zs-13595, 1:200), goat polyclonal anti-MMP-9 antibody (zs-6840, 1:100), rabbit polyclonal anti-TIMP-1 antibody (sc-5538, 1:300), rabbit polyclonal anti-TIMP-2 antibody (zs-5539, 1:300), goat polyclonal antiICAM-1 antibody (zs-1511, 1:200), goat polyclonal anti-TNF- $\alpha$ antibody (sc-1350, 1:200) and mouse polyclonal anti- $\beta$-actin antibody (sc-47778, 1:2000) were purchased from Santa Cruz Biotechnology (Santa Cruz, CA, USA). The immunoreactive bands were visualized with the corresponding horseradish peroxidase-conjugated secondary antibodies and Super ECL Plus (Applygen Technologies, Beijing, China). Relative protein expression was quantified by densitometry using Quantity One software (Bio-Rad Laboratories, Hercules, CA, USA).

Statistical analysis. All statistical analyses was performed using SPSS software (version 16.0; SPSS Inc., Chicago, IL, USA) and data are expressed as the means \pm SD. Statistical analyses were performed using one-way ANOVA with Fisher's least significant difference (LSD) or Dunnett's T3 test. A value of $\mathrm{P}<0.05$ was considered to indicate a statistically significant difference.

\section{Results}

Effects of PCPA on MCT-induced changes in hemodynamics and $R V I$. The rats were fed for 3 weeks; during this period, 8 out of 17 rats died in the MCT group (mortality rate, $47.1 \%$; $\mathrm{P}<0.01$ vs. control). One out of 17 rats died in the MCT $+\mathrm{P} 1$ group (mortality rate, $5.9 \% ; \mathrm{P}<0.01$ vs. $\mathrm{MCT}$ ).

Compared with the control group, PAP and RV/LV $+\mathrm{S}$ in the MCT group were markedly elevated, and body weight was decreased. Compared with the MCT group, PCPA significantly decreased PAP and $\mathrm{RV} / \mathrm{LV}+\mathrm{S}$. The heart rate and SAP showed no significant differences among the 4 groups (Table I).

Effects of PCPA on pulmonary vascular histology. Rats in the MCT group showed a marked increase in the average medial wall thickness of the pulmonary arteries. The percentage of medial wall thickness increased from 19.1 $7.7 \%$ (control group) to $49.7 \pm 9.2 \%$ (MCT group) $(\mathrm{P}<0.01)$, and the percentage in the MCT $+\mathrm{P} 1$ and $\mathrm{MCT}+\mathrm{P} 2$ groups decreased to $34.3 \pm 8.2 \%(\mathrm{P}<0.01$ vs. $\mathrm{MCT})$ and $28.1 \pm 10.7 \%(\mathrm{P}<0.01$ vs. MCT), respectively (Fig. 1). The percentage of the wall area of pulmonary arteries in the MCT group markedly increased from $34.4 \pm 9.2 \%$ to $60.5 \pm 8.0 \%$ ( $\mathrm{P}<0.01$ vs. control). Compared with the MCT group, the percentage of medial wall thickness of pulmonary arteries in the MCT $+\mathrm{P} 1$ and $\mathrm{MCT}+\mathrm{P} 2$ groups decreased to $51.4 \pm 4.5 \%(\mathrm{P}<0.05)$ and $43.8 \pm 5.8 \%(\mathrm{P}<0.01)$, respectively. These results demonstrated that $\mathrm{MCT}$ induced pulmonary vascular remodeling, whereas PCPA attenuated the effects of MCT (Fig. 1). 

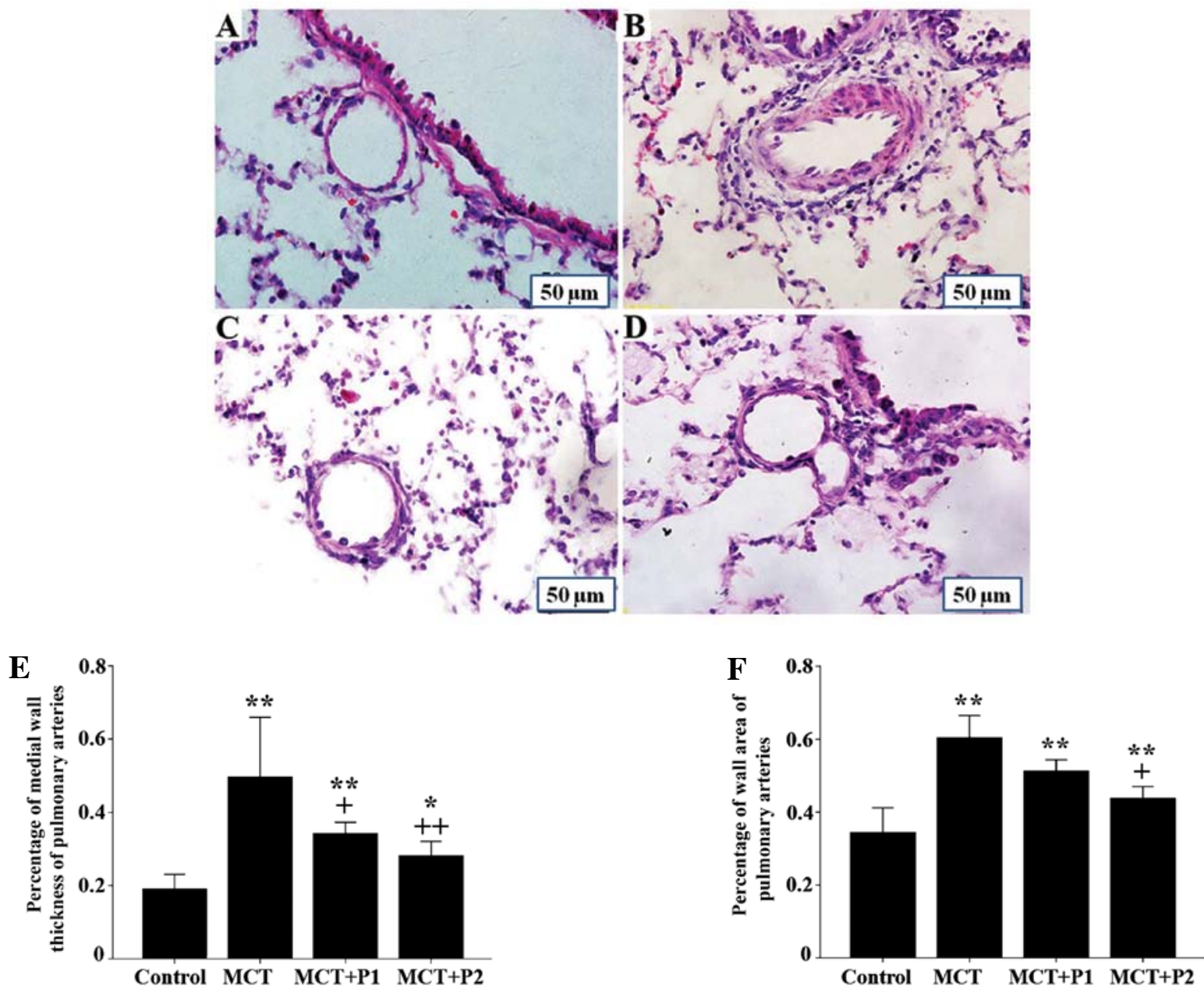

Figure 1. Effects of 4-chloro-DL-phenylalanine (PCPA) on the pulmonary arterial wall thickness ratio. Lung tissues obtained from (A) the control group, (B) the monocrotaline (MCT) group, (C) MCT plus $50 \mathrm{mg} / \mathrm{kg}$ body mass PCPA group (MCT + P1), and (D) MCT plus $100 \mathrm{mg} / \mathrm{kg}$ body mass PCPA group $(\mathrm{MCT}+\mathrm{P} 2)$. Pulmonary vascular remodeling measured as a percentage of (E) medial wall thickness and (F) wall area of pulmonary arteries in the 4 groups. Data are expressed as the means $\pm \mathrm{SD}(\mathrm{n}=3) .{ }^{*} \mathrm{P}<0.05,{ }^{* *} \mathrm{P}<0.01$ compared with the control group. ${ }^{+} \mathrm{P}<0.05$ and ${ }^{++} \mathrm{P}<0.01$ compared with the MCT group (Original magnification, $\mathrm{x} 400$, scale bars, $50 \mu \mathrm{m}$ ).

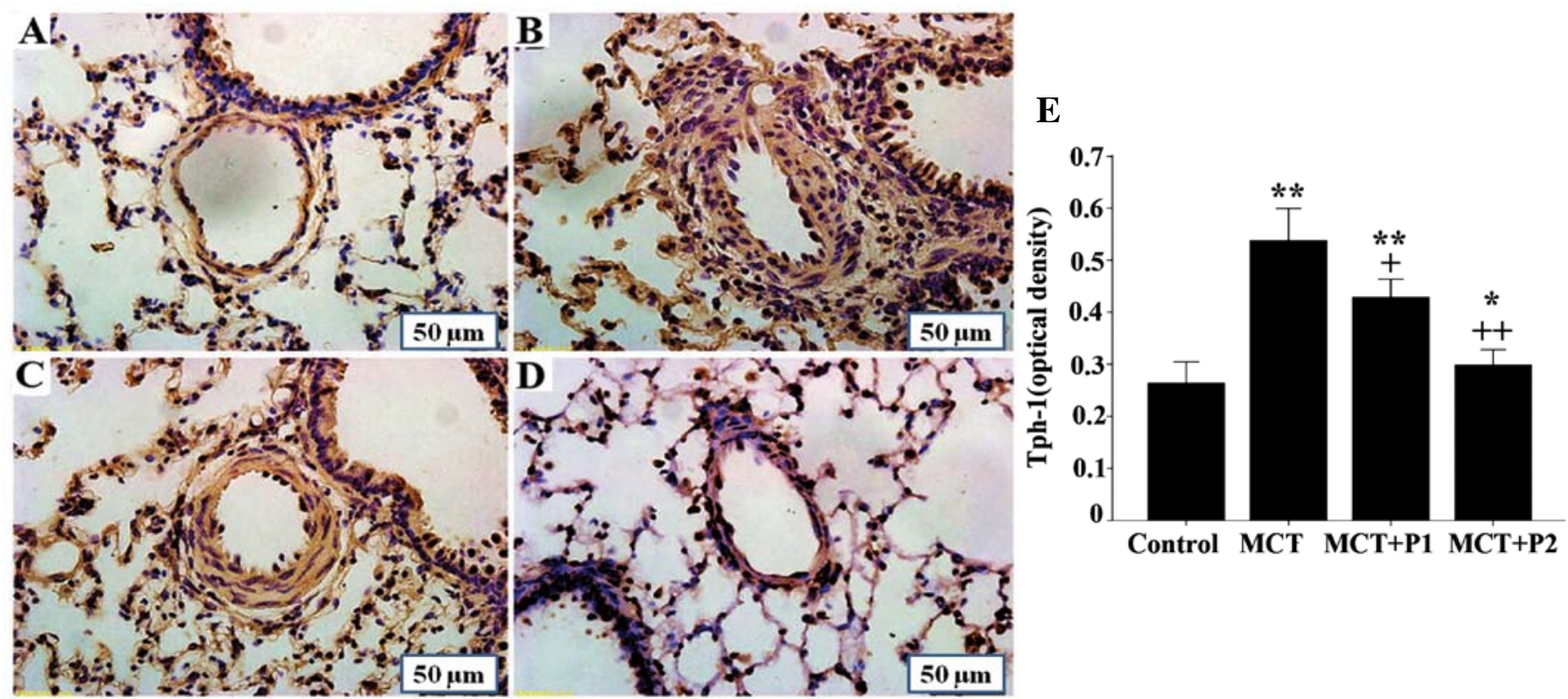

Figure 2. Immunohistochemical determination of tryptophan hydroxylase-1 (Tph-1) protein expression in pulmonary arteries. (A) The control group, (B) the monocrotaline (MCT) group, (C) MCT plus $50 \mathrm{mg} / \mathrm{kg}$ body mass 4-chloro-DL-phenylalanine (PCPA) group (MCT + P1), and (D) MCT plus $100 \mathrm{mg} / \mathrm{kg}$ body mass PCPA group (MCT + P2). (Original magnification; $\mathrm{x} 400$, scale bars, $50 \mu \mathrm{m})$. (E) Average optical density of Tph-1 in rat lungs. Data are the means $\pm \mathrm{SD}$ $(\mathrm{n}=3) .{ }^{*} \mathrm{P}<0.05,{ }^{* *} \mathrm{P}<0.01$ compared with the control group. ${ }^{+} \mathrm{P}<0.05$ and ${ }^{++} \mathrm{P}<0.01$ compared with the MCT group. 

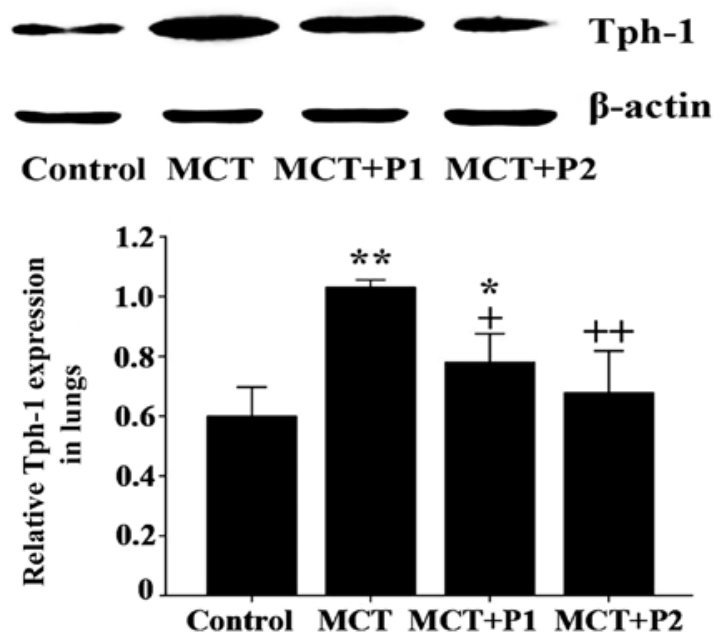

Figure 3. Western blot analysis of tryptophan hydroxylase-1 (Tph-1) expression in the rat lungs in the different groups: the control group, the monocrotaline (MCT)-induced pulmonary arterial hypertension group and the 50 and $100 \mathrm{mg} / \mathrm{kg}$ 4-chloro-DL-phenylalanine (PCPA) treated groups (MCT + P1 and MCT $+P 2$, respectively). Data are expressed as the means \pm SD $(n=5)$. ${ }^{*} \mathrm{P}<0.05,{ }^{* *} \mathrm{P}<0.01$ compared with the control group. ${ }^{+} \mathrm{P}<0.05$ and ${ }^{++} \mathrm{P}<0.01$ compared with the MCT group.

Effect of PCPA on Tph-1 expression in rat lungs. Immunohistochemistry using anti-Tph-1 antibodies revealed a strong Tph-1 expression in the lungs of rats with MCT-induced PAH compared with the control group. Treatment with PCPA (50 mg/kg/day) slightly reversed the MCT-induced increase in Tph-1 protein expression in the lungs. However, treatment with PCPA (100 mg/kg/day) reduced the MCT-induced increase in Tph-1 expression significantly (Fig. 2).
Western blot analysis revealed that the level of Tph-1 protein expression significantly increased in the MCT group compared with the control group $(1.03 \pm 0.01$ vs. $0.59 \pm 0.04$, respectively, $\mathrm{P}<0.01)$. At $50 \mathrm{mg} / \mathrm{kg}$, PCPA attenuated the MCT-induced increase in the expression of Tph-1 protein in the rat lungs $(0.78 \pm 0.04, \mathrm{P}<0.05 \mathrm{vs}$. MCT). At $100 \mathrm{mg} / \mathrm{kg}, \mathrm{PCPA}$ significantly suppressed the MCT-induced expression of Tph-1 protein $(0.67 \pm 0.05, \mathrm{P}<0.01$ vs. MCT, Fig. 3$)$.

Effect of PCPA on SERT expression in rat lungs. The results of immunohistochemical analysis revealed that the expression of SERT was markedly upregulated in the lung tissues of the MCT group compared with the control group. Treatment with PCPA attenuated the MCT-induced increase in SERT expression (Fig. 4).

Consistent with the results of immunohistochemical analysis, western blot analysis revealed that SERT protein expression was significantly increased in the MCT group compared with the control group $(1.47 \pm 0.07$ vs. $0.73 \pm 0.01$, respectively, $\mathrm{P}<0.01)$. At $50 \mathrm{mg} / \mathrm{kg}, \mathrm{PCPA}$ attenuated the MCT-induced expression of SERT protein in the rat lungs $(1.16 \pm 0.09, \mathrm{P}<0.05$ vs. MCT). At $100 \mathrm{mg} / \mathrm{kg}$, PCPA significantly suppressed the MCT-induced expression of SERT protein $(0.84 \pm 0.05, \mathrm{P}<0.01$ vs. MCT, Fig. 5).

Effects of PCPA on MMP activity and protein expression. Gelatin zymography was used to evaluate the effects of PCPA on the activity of MMP-2 and MMP-9 in MCT-induced PAH. The activity of MMP-2 and MMP-9 significantly increased with MCT treatment $(745 \pm 37$ and $701 \pm 90, \mathrm{P}<0.01$ and $\mathrm{P}<0.05$, respectively), compared with the control group $(n=5)$. Following treatment with PCPA (50 mg/kg/day), the increased MMP-2 activity showed a decreasing trend $(636 \pm 92, n=5)$; however,

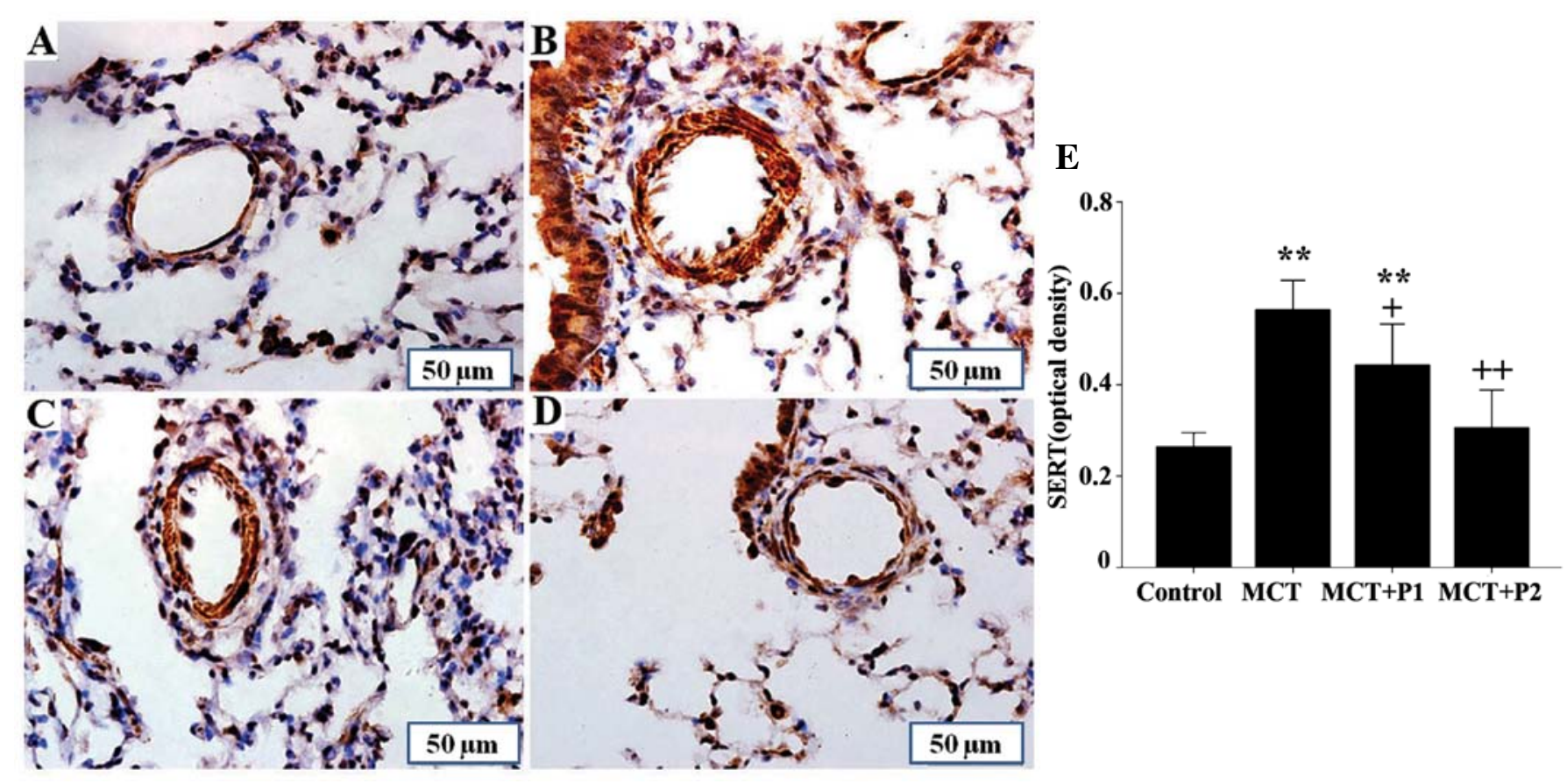

Figure 4. Immunohistochemical determination of serotonin transporter (SERT) protein expression in pulmonary arteries. (A) The control group, (B) the monocrotaline (MCT) group, (C) MCT plus $50 \mathrm{mg} / \mathrm{kg}$ body mass 4-chloro-DL-phenylalanine (PCPA) group (MCT + P1), and (D) MCT plus $100 \mathrm{mg} / \mathrm{kg}$ body mass PCPA group (MCT + P2). (Original magnification; x400 scale bars, $50 \mu \mathrm{m}$ ). (E) Average optical density of SERT in rat lungs. Data are the means \pm SD $(\mathrm{n}=3) .{ }^{* *} \mathrm{P}<0.01$ compared with the control group. ${ }^{+} \mathrm{P}<0.05$ and ${ }^{++} \mathrm{P}<0.01$ compared with the MCT group. 

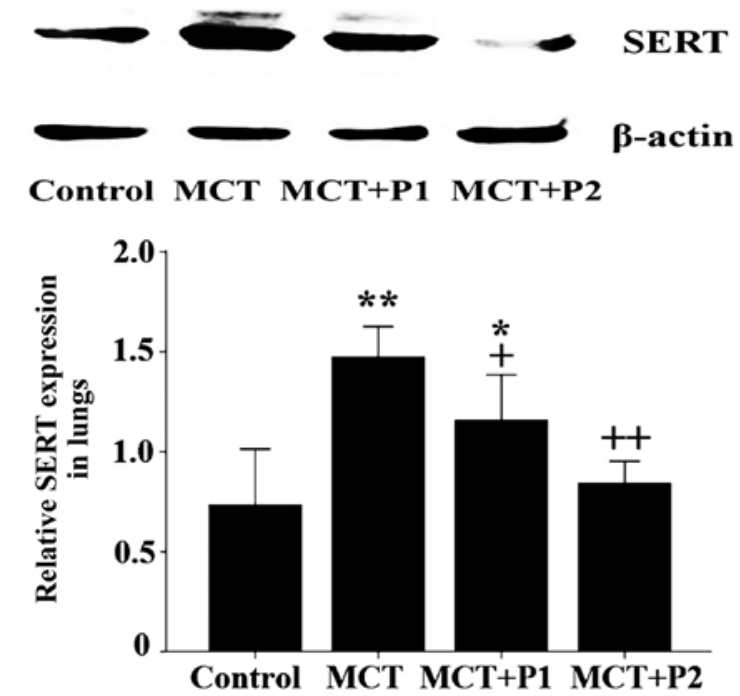

Figure 5. Western blot analysis of serotonin transporter (SERT) expression in rat lungs in the different groups: the control group, the monocrotaline (MCT)-induced pulmonary arterial hypertension group and the 50 and $100 \mathrm{mg} / \mathrm{kg}$ 4-chloro-DL-phenylalanine (PCPA) treated groups (MCT + P1 and MCT $+\mathrm{P} 2$, respectively). Data are expressed as the means $\pm \mathrm{SD}(\mathrm{n}=5)$. ${ }^{*} \mathrm{P}<0.05,{ }^{* *} \mathrm{P}<0.01$ compared with the control group. ${ }^{+} \mathrm{P}<0.05$ and ${ }^{++} \mathrm{P}<0.01$ compared with the MCT group.

the effect was not obvious. Following treatment with a higher dose of PCPA (100 mg/kg/day), the increased MMP-2 activity markedly decreased to a level similar to that of the control $(472 \pm 82, \mathrm{P}<0.05$ vs. MCT). There was also a decreasing trend in the activity of MMP-9 following PCPA treatment; in the MCT + P1 group, MMP-9 activity decreased to $592 \pm 68$ and in the MCT + P2 group, it decreased to $504 \pm 73$ ( $\mathrm{P}<0.05$ vs. MCT, Fig. 6).

The protein expression of MMP-2, MMP-9, TIMP-1 and TIMP-2 was determined by western blot analysis. Compared with the control group, the protein expression of MMP-2, MMP-9, TIMP-1 and TIMP-2 in the MCT group was increased from $0.81 \pm 0.13$ to $1.40 \pm 0.07$ ( $\mathrm{P}<0.01$ vs. control, Fig. 7A), $0.72 \pm 0.07$ to $1.24 \pm 0.02$ ( $\mathrm{P}<0.01$ vs. control, Fig. $7 \mathrm{~B}$ ), $0.48 \pm 0.10$ to $1.18 \pm 0.08$ ( $\mathrm{P}<0.01$ vs. control, Fig. $7 \mathrm{C})$, and from $0.67 \pm 0.12$ to $1.37 \pm 0.20(\mathrm{P}<0.01$ vs. control, Fig. $7 \mathrm{D})$, respectively $(\mathrm{n}=5)$. Of note, PCPA inhibited the MCT-induced increase in MMP-2/-9, and TIMP-1/-2 expression in a dose-dependent manner. In the MCT + P1 group, the MMP-9 and TIMP-1 levels decreased to $0.95 \pm 0.06$ and $0.86 \pm 0.08$, respectively (both $\mathrm{P}<0.05$ vs. MCT). However, the MMP-2 and TIMP-2 levels decreased to $1.14 \pm 0.08$ and $1.01 \pm 0.1$, respectively, although the differences did not reach statistical significance compared with the MCT group. In the MCT + P2 group, the MMP-2, MMP-9, TIMP-1 and TIMP-2 levels significantly decreased to $1.02 \pm 0.1(\mathrm{P}<0.05$ vs. MCT), $0.88 \pm 0.02$ ( $\mathrm{P}<0.01$ vs. MCT), $0.76 \pm 0.08$ ( $\mathrm{P}<0.01$ vs. $\mathrm{MCT}$ ), and $0.84 \pm 0.05(\mathrm{P}<0.05$ vs. MCT), respectively (Fig. 7).

Effects of PCPA on lung inflammation. As shown in Fig. 8, a marked perivascular inflammatory cell infiltration and a significant increase in the number of inflammatory cells was observed in the MCT group. PCPA at a dose of 50 and $100 \mathrm{~kg} /$ day markedly decreased MCT-induced lung inflammation.

Western blot analysis revealed that the levels of IL-1 $\beta$, TNF- $\alpha$ and ICAM-1 in the MCT group were notably increased
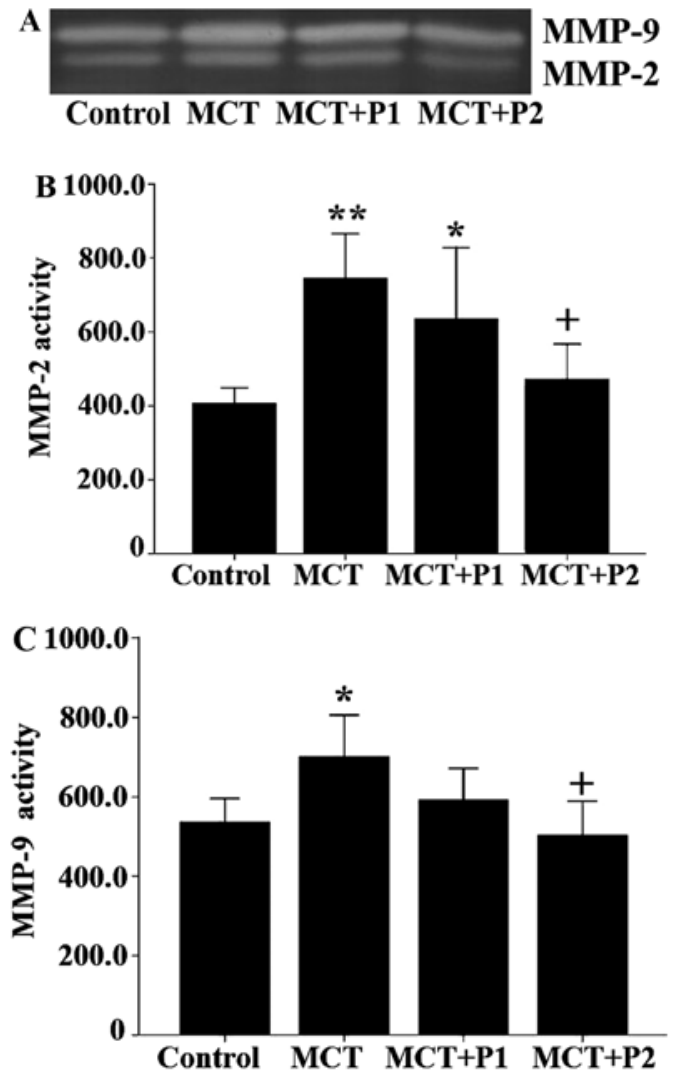

Figure 6. Effect of 4-chloro-DL-phenylalanine (PCPA) on monocrotaline (MCT)-induced matrix metalloproteinases-2 (MMP-2) and MMP-9 activities in rat lungs. (A) Representative zymograms for MMP-2 and MMP-9 in the control group, the MCT group, MCT plus $50 \mathrm{mg} / \mathrm{kg}$ body mass PCPA group (MCT + P1) group, and MCT plus $100 \mathrm{mg} / \mathrm{kg}$ body mass PCPA group $(\mathrm{MCT}+\mathrm{P} 2)$. Activities of (B) MMP-2 and (C) MMP-9 relative to the control are shown as the means $\pm \mathrm{SD}(\mathrm{n}=5) .{ }^{*} \mathrm{P}<0.05,{ }^{* *} \mathrm{P}<0.01$ compared with the control group. ${ }^{+} \mathrm{P}<0.05$ compared with the MCT group.

compared with control group. IL-1 $\beta$ expression increased in the MCT group from $0.63 \pm 0.04$ to $1.44 \pm 0.11$ ( $\mathrm{P}<0.01$ vs. control, $\mathrm{n}=5)$. In the MCT $+\mathrm{P} 1$ and $\mathrm{MCT}+\mathrm{P} 2$ groups, IL-1 $\beta$ expression decreased to $0.99 \pm 0.02(\mathrm{P}<0.05$ vs. $\mathrm{MCT})$ and $0.77 \pm 0.11$ $(\mathrm{P}<0.01$ vs. MCT, Fig. 9A), respectively. TNF- $\alpha$ expression increased in the MCT group from $0.64 \pm 0.08$ to $1.14 \pm 0.09$ $(\mathrm{P}<0.01$ vs. control, $\mathrm{n}=5)$. In the $\mathrm{MCT}+\mathrm{P} 1$ and $\mathrm{MCT}+\mathrm{P} 2$ groups, TNF- $\alpha$ expression decreased to $0.84 \pm 0.06$ ( $\mathrm{P}<0.05$ vs. MCT) and $0.77 \pm 0.07(\mathrm{P}<0.05$ vs. MCT, Fig. 9B), respectively. ICAM-1 expression increased in the MCT group from $0.45 \pm 0.02$ to $1.61 \pm 0.26(\mathrm{P}<0.01$ vs. control, $\mathrm{n}=5)$. In the $\mathrm{MCT}+\mathrm{P} 1$ and $\mathrm{MCT}+\mathrm{P} 2$ groups, ICAM-1 expression decreased to $1.24 \pm 0.12$ and $0.98 \pm 0.15$ ( $\mathrm{P}<0.05$ vs. MCT, Fig. 9C), respectively. PCPA inhibited the MCT-induced increase in the expression of these inflammatory cytokines (Fig. 9).

\section{Discussion}

The results of the present study demonstrated that MCT markedly elevated PAP, RV/LV $+\mathrm{S}$, pulmonary vascular remodeling, as well as lung inflammation and mortality, accompanied with an increased expression of Tph-1, SERT, MMPs/TIMPs and inflammatory cytokines (IL-1 $\beta$, TNF- $\alpha$ and ICAM-1). Our results also revealed that PCPA dose dependently inhibited the MCT-induced increase in PAP, $\mathrm{RV} / \mathrm{LV}+\mathrm{S}$, pulmonary 


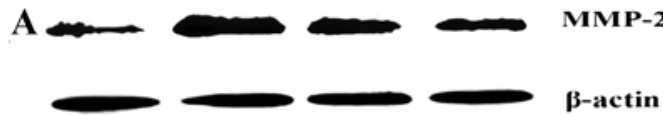

Control MCT MCT+P1 MCT+P2

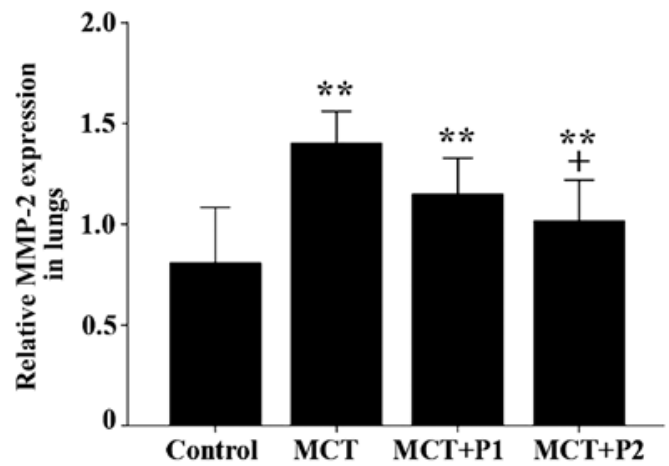

$\mathrm{C} b \longrightarrow$ TIMP-1

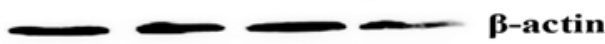

Control MCT MCT+P1 MCT+P2

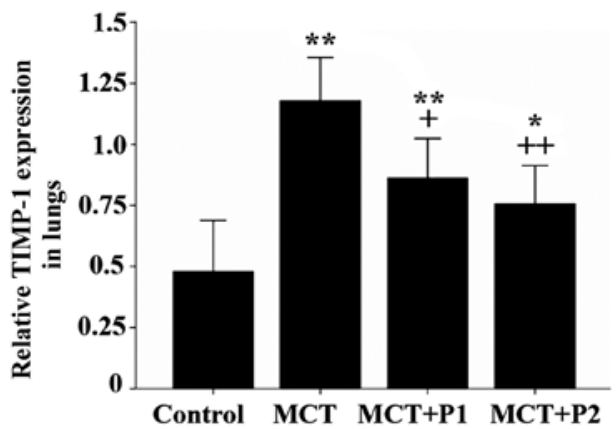

B

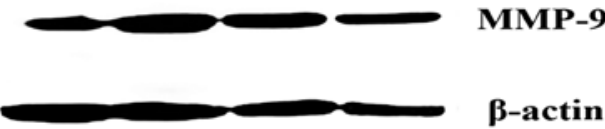

Control MCT MCT+P1 MCT+P2

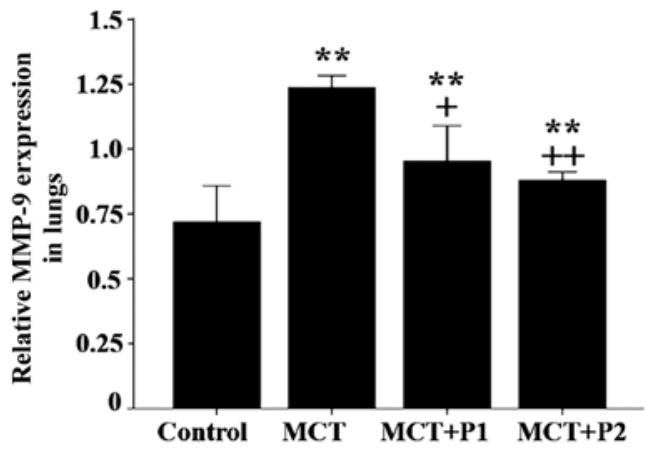

D

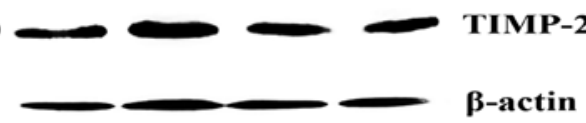

Control MCT MCT+P1 MCT+P2

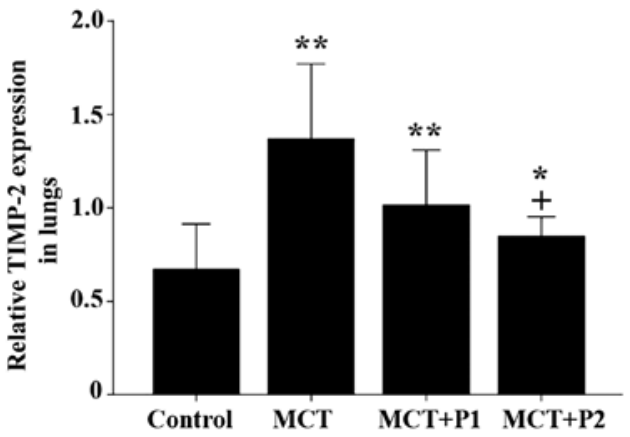

Figure 7. Western blot analysis of (A) matrix metalloproteinases-2 (MMP-2) protein, (B) MMP-9 protein, (C) tissue inhibitors of metalloproteinases-1 (TIMP-1) protein, and (D) TIMP-2 protein expression in the rat lungs in the different groups. The control group, the monocrotaline (MCT)-induced pulmonary arterial hypertension group and the 50 and $100 \mathrm{mg} / \mathrm{kg}$ 4-chloro-DL-phenylalanine (PCPA) treated groups (MCT + P1 and MCT + P2, respectively). Data are expressed as the means $\pm \mathrm{SD}(\mathrm{n}=5) .{ }^{*} \mathrm{P}<0.05,{ }^{* *} \mathrm{P}<0.01$ compared with the control group. ${ }^{+} \mathrm{P}<0.05$ and ${ }^{++} \mathrm{P}<0.01$ compared with the MCT group.
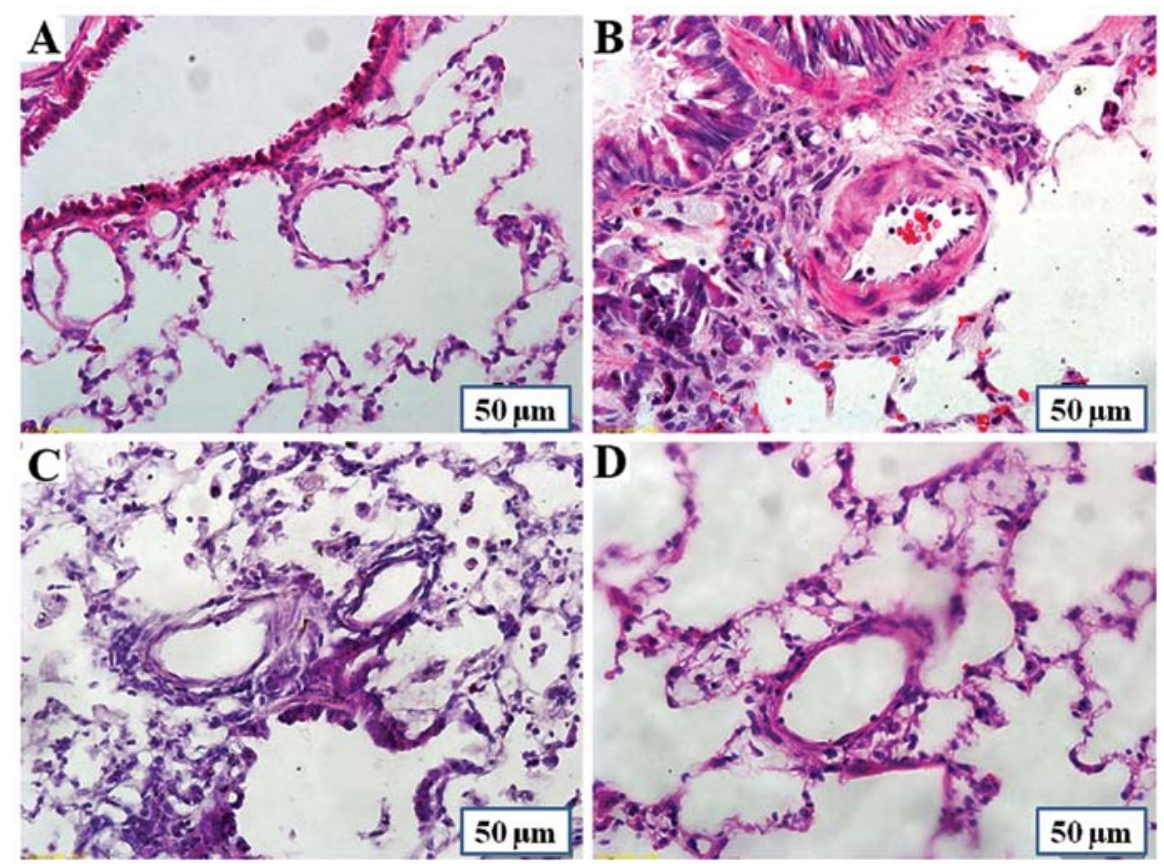

Figure 8. Comparison of lung inflammatory changes illustrated by respresentative photomicrographs. (A) The control group, (B) the monocrotaline (MCT) group, (C) MCT plus $50 \mathrm{mg} / \mathrm{kg}$ body mass 4-chloro-DL-phenylalanine (PCPA) group (MCT + P1), and (D) MCT plus $100 \mathrm{mg} / \mathrm{kg}$ body mass PCPA group (MCT + P2). (Original magnification, $\mathrm{x} 400$; scale bars, $50 \mu \mathrm{m})$. 
A

IL-1 B
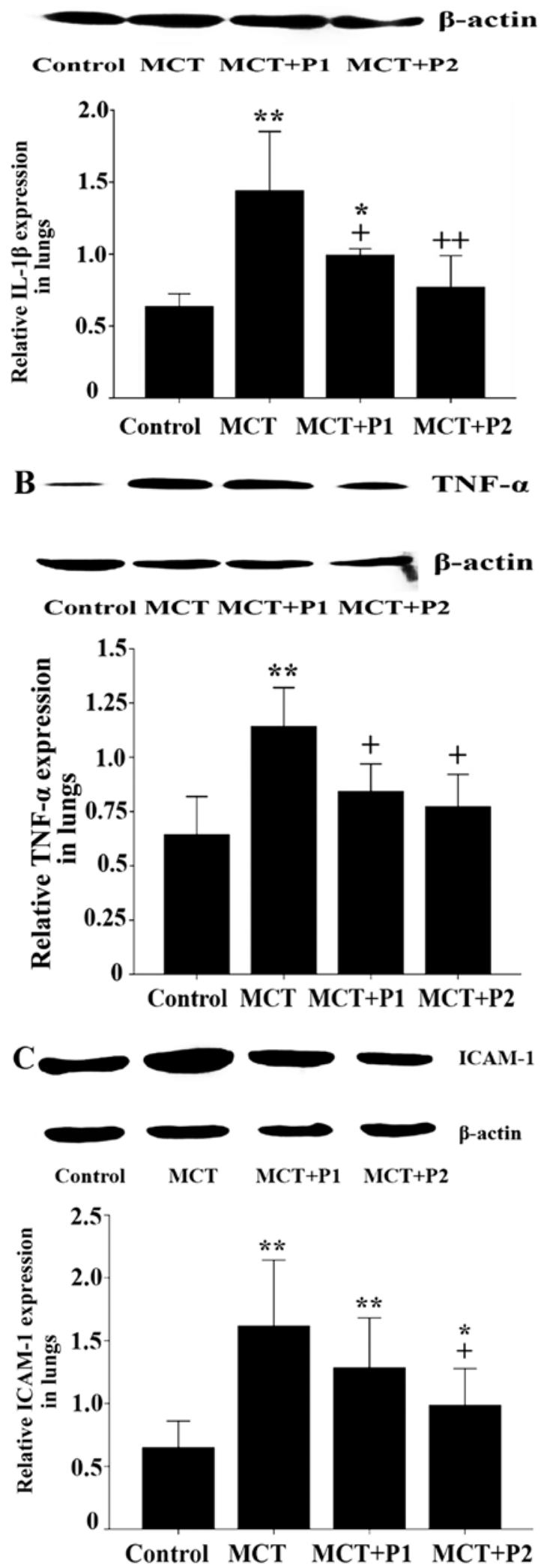

Figure 9. Western blot analysis of (A) interleukin-1 $\beta$ (IL-1 $\beta$ ) protein, (B) tumor necrosis factor- $\alpha$ (TNF- $\alpha$ ) protein, and (C) intercellular adhesion molecule-1 (ICAM-1) protein expression in the rat lungs in the different groups. The control group, the monocrotaline (MCT)-induced pulmonary arterial hypertension group and the 50 and $100 \mathrm{mg} / \mathrm{kg}$ 4-chloro-DL-phenylalanine (PCPA) treated groups $(\mathrm{MCT}+\mathrm{P} 1$ and $\mathrm{MCT}+\mathrm{P} 2$, respectively). Data are expressed as mean $\pm \mathrm{SD}(\mathrm{n}=5) .{ }^{*} \mathrm{P}<0.05,{ }^{* *} \mathrm{P}<0.01$ compared with the control group. ${ }^{+} \mathrm{P}<0.05$ and ${ }^{++} \mathrm{P}<0.01$ compared with the MCT group. vascular remodeling and lung inflammation, and decreased the mortality rate, accompanied by the suppression of Tph-1, SERT, MMPs/TIMPs and inflammatory cytokine (IL-1 $\beta$, TNF- $\alpha$ and ICAM-1) expression.

Serotonin is recognized as one of the most important growth factors in PAH, and the levels of plasma 5-HT have been shown to be markedly elevated in patients with PAH (26). 5-HT is involved in the development of PAH with pulmonary vascular remodeling, including the migration and proliferation of smooth muscle cells (27). It is known that the critical step in 5-HT biosynthesis is catalyzed by the rate-limiting enzyme, Tph (19), and that Tph-1 is the chief enzyme responsible for the synthesis of peripheral 5-HT (31). Tph expression and 5-HT synthesis have been shown to be increased in pulmonary endothelial cells from patients with IPAH and hypoxia-induced PAH in rats $(16,19)$. The adenovirus-mediated knockdown of pulmonary endothelial Tph-1 has been shown to attenuate hypoxia-induced $\mathrm{PH}$ (28); in addition, $\mathrm{Tph}^{-/-}$mice display markedly reduced plasma levels of 5-HT (29). These data indicate that Tph-1 plays an important role in the development of PAH. On the other hand, the overexpression of SERT is a common pathogenic mechanism in various forms of human $\mathrm{PH}$ and animal pathogenic models $(5,15,30)$. These data from other studies are accordance with those of our present study, namely that the expression of Tph-1 and SERT was markedly increased in the lungs of rats in the MCT group.

As previously demonstrated, PCPA markedly inhibited 5-HT synthesis through the inhibition of Tph-1. Valzelli et al (32) reported that PCPA acted as a competitive and irreversible inhibitor of Tph, the rate-limiting enzyme in 5-HT synthesis, used to deplete brain serotonin. Treatment of $\mathrm{TPH} 1^{+/+}$ mice with PCPA significantly decreased the level of 5-HT in the colon (33). When a theta-burst stimulation was applied in layer $2 / 3$ of 5 -HT depleted cortical slices (following in vivo treatment with the Tph inhibitor, PCPA), it was observed that there was a persistent shift in the ratio between excitation and inhibition, in the favour of inhibition (34). An intraperitoneal injection of PCPA has been shown to selectively impair 5HT-containing nerve terminals and fibers (35). In our previous studies, we demonstrated that the inhibition of SERT by the selective serotonin reuptake inhibitor (SSRI), fluoxetine, significantly inhibited MCT-induced PAH and the 5-HT-induced proliferation of PASMCs $(25,36,37)$. In the present study, we observed that PCPA markedly suppressed the expression of Tph-1 and SERT. The modulation of SERT levels can influence the availability of 5-HT in the synaptic cleft (38). In a previous study, after a single intraperitoneal injection of PCPA, there was a rapid downregulation in SERT mRNA levels in the cell bodies (38). These findings suggest that PCPA inhibits 5-HT by suppressing Tph-1, regulating SERT and the serotonin downstream signaling pathway.

The MMP axis plays a crucial role in the development of $\mathrm{PH}$, as well as in the disease states specifically with regard to ECM remodeling and vascular homeostasis (39). Previous studies had shown that increased MMP activity and expression enhances vascular remodeling in human and animal models of PAH $(40,41)$. The activity of MMPs is regulated by TIMPs and the balance between MMPs and TIMPs plays an important role in vascular remodeling, angiogenesis and vasodilatation (41). A higher expression of MMP-2, MMP-9, TIMP-1 and 
TIMP-2 in the lungs has been found in rats with MCT-induced PAH (3). This may be associated with the damage to pulmonary arterial endothelial cells induced by MCT and pulmonary inflammation (42). Consistent with previous results, the present results demonstrated that $\mathrm{MCT}$ induced an increased in the expression of MMP-2, MMP-9, TIMP-1 and TIMP-2 in the lung tissue. We also found that PCPA markedly attenuated pulmonary vascular remodeling, suppressed MMP-2, MMP-9 enzymatic activity, and decreased MMP-2, MMP-9/TIMP-1, TIMP-2 expression in a dose-dependent manner.

Certain studies have reported that serotonin induces MMP production via SERT, protein kinase $C$, phospholipase $C$, the extracellular signal-regulated kinase (ERK) 1/2 pathway in smooth muscle cells and the RhoA-ROCK and Akt signaling pathways $(25,43)$. The serotonin intracellular signaling pathway may be involved in the inhibition of ECM remodeling by fluoxetine (3). Based on the inhibitory effects of PCPA on Tph-1 and 5-HT, we hypothesized that the PCPA-induced regulation of MMP-2, MMP-9/TIMP-1, TIMP-2 is ascribed to the suppression of pulmonary vascular remodeling, in which the serotonin intracellular signaling pathway may be involved.

Inflammatory mechanisms play a prominent role in the pathogenesis of PAH by contributing to the development and progressino of $\mathrm{PAH}$; they have also been implicated as a triggering factor in PAH $(44,45)$. It had been demonstrated that serotonin is closely related to inflammation, including the activation of alveolar macrophages, the development and maintenance of vascular remodeling, and the induction of mast cell adhesion and migration through the release of cytokines (46-48). In our previous study, we demonstrated that SSRI fluoxetine protected against MCT-induced lung inflammation by inhibiting SERT (3), which indicated that SERT may participate in the process of inflammation. The levels of inflammatory cytokines, such as monocyte chemoattractant protein-1 (MCP-1), IL-6, IL-1 $\beta$, ICAM-1 and TNF- $\alpha$ are markedly increased in patients with IPAH and in animal experimental models of PAH $(3,49,50)$. Further evidence indicates that there are significantly higher amounts of IL-1 $\beta$ and IL-6 in the culture supernatants of lipopolysaccharidestimulate macrophages following incubation with 5-HT (33). The inhibition of 5-HT synthesis by PCPA not only attenuates the severity of inflammation associated with dextran sodium sulfate (DSS)-induced colitis, but also reduces the production of pro-inflammatory mediators in the gut (33). These findings are consistent with the observation of the reduction in colonic IL-1 $\beta$, IL- 6 and TNF- $\alpha$ levels in Tph $1^{-/}$mice treated with PCPA following DSS administration (33). The present study on MCT-induced lung inflammation also demonstrated an increase in ICAM-1, IL- $1 \beta$ and TNF- $\alpha$ levels in the lungs, which is in accordance with the above-mentioned evidence. This study also demonstrated that PCPA markedly inhibited lung inflammatory responses in MCT-induced $\mathrm{PAH}$ in rats and showed that this inhibition was accompanied by the attenuated expression of inflammatory cytokines, including IL-1 $\beta$, TNF- $\alpha$ and ICAM-1.

In conclusion, the Tph-1 inhibitor, PCPA, protects against MCT-induced pulmonary vascular remodeling and lung inflammation, which is associated with the downregulation in the expression of Tph-1, SERT, MMPs/TIMPs and inflammatory cytokines in rats.

\section{Acknowledgements}

This study was supported by grants from the National Natural Science Foundation of China (No. 81273511 and No. 30572194) and No. 30973533.

\section{References}

1. MacLean MR: Pulmonary hypertension and the serotonin hypothesis: where are we now? Int J Clin Pract Suppl: 27-31, 2007.

2. Dewachter L, Adnot S, Fadel E, et al: Angiopoietin/Tie2 pathway influences smooth muscle hyperplasia in idiopathic pulmonary hypertension. Am J Respir Crit Care Med 174: 1025-1033, 2006.

3. Li XQ, Wang HM, Yang CG, Zhang XH, Han DD and Wang HL: Fluoxetine inhibited extracellular matrix of pulmonary artery and inflammation of lungs in monocrotaline-treated rats. Acta Pharmacol Sin 32: 217-222, 2010.

4. Crapo PM, Medberry CJ, Reing JE, Tottey S, Van der Merwe Y, Jones KE and Badylak SF: Biologic scaffolds composed of central nervous system extracellular matrix. Biomaterials 33: 3539-3547, 2012.

5. Wang Y, Han DD, Wang HM, Liu M, Zhang XH and Wang HL: Downregulation of osteopontin is associated with fluoxetine amelioration of monocrotaline-induced pulmonary inflammation and vascular remodelling. Clin Exp Pharmacol Physiol 38: 365-372, 2011.

6. Giantin M, Aresu L, Benali S, et al: Expression of matrix metalloproteinases, tissue inhibitors of metalloproteinases and vascular endothelial growth factor in canine mast cell tumours. J Comp Pathol 147: 419-429, 2012.

7. Umesh A, Paudel O, Cao YN, Myers AC and Sham JS: Alteration of pulmonary artery integrin levels in chronic hypoxia and monocrotaline-induced pulmonary hypertension. J Vasc Res 48: 525-537, 2011.

8. Price LC, Wort SJ, Perros F, et al: Inflammation in pulmonary arterial hypertension. Chest 141: 210-221, 2012.

9. Tuder RM, Groves B, Badesch DB and Voelkel NF: Exuberant endothelial cell growth and element of inflammation are present in plexiform lesions of pulmonary hypertension. Am J Pathol 144: 275-285, 1994.

10. Bauer EM, Zheng H, Comhair S, Erzurum S, Billiar TR and Bauer PM: Complement C3 deficiency attenuates chronic hypoxia-induced pulmonary hypertension in mice. PLoS One 6: e28578, 2011.

11. Rashid M, Fahim M and Kotwani A: Efficacy of tadalafil in chronic hypobaric hypoxia-induced pulmonary hypertension: possible mechanisms. Fundam Clin Pharmacol 27: 271-278, 2013.

12. Li M, Riddle SR, Frid MG, et al: Emergence of fibroblasts with a proinflammatory epigenetically altered phenotype in severe hypoxic pulmonary hypertension. J Immunol 187: 2711-2722, 2011.

13. Guignabert $\mathrm{C}$, Raffestin $\mathrm{B}$, Benferhat $\mathrm{R}$, et al: Serotonin transporter inhibition prevents and reverses monocrotaline-induced pulmonary hypertension in rats. Circulation 111: 2812-2819, 2005.

14. Fanburg BL and Lee SL: A new role for an old molecule: serotonin as a mitogen. Am J Physiol 272: L795-L806, 1997.

15. Marcos E, Fadel E, Sanchez O, et al: Serotonin-induced smooth muscle hyperplasia in various forms of human pulmonary hypertension. Circ Res 94: 1263-1270, 2004.

16. Eddahibi S, Guignabert C, Barlier-Mur AM, et al: Cross talk between endothelial and smooth muscle cells in pulmonary hypertension: critical role for serotonin-induced smooth muscle hyperplasia. Circulation 113: 1857-1864, 2006.

17. Morrell NW, Adnot S, Archer SL, et al: Cellular and molecular basis of pulmonary arterial hypertension. J Am Coll Cardiol 54 (Suppl 1): S20-S31, 2009.

18. Rothman RB, Cadet JL, Dersch CM, et al: Altered gene expression in pulmonary tissue of tryptophan hydroxylase-1 knockout mice: implications for pulmonary arterial hypertension. PLoS One 6: e17735, 2011.

19. Izikki M, Hanoun N, Marcos E, et al: Tryptophan hydroxylase 1 knockout and tryptophan hydroxylase 2 polymorphism: effects on hypoxic pulmonary hypertension in mice. Am J Physiol Lung Cell Mol Physiol 293: L1045-L1052, 2007. 
20. Margolis KG and Pothoulakis C: Serotonin has a critical role in the pathogenesis of experimental colitis. Gastroenterology 137: 1562-1566, 2009.

21. Tucker A, Bryant SE, Frost HH and Miqally N: Chemical sympathectomy and serotonin inhibition reduce monocrotalineinduced right ventricular hypertrophy in rats. Can J Physiol Pharmacol 61: 356-362, 1983.

22. Liu M, Wang Y, Wang HM, Bai Y, Zhang XH, Sun YX and Wang HL: Fluoxetine attenuates chronic methamphetamineinduced pulmonary arterial remodeling: possible involvement of serotonin transporter and serotonin 1B receptor. Basic Clin Pharmacol Toxicol 112: 77-82, 2013.

23. Agard C, Rolli-Derkinderen M, Dumas-de-La-Roque E, et al: Protective role of the antidiabetic drug metformin against chronic experimental pulmonary hypertension. Br J of Pharmacol 158 : 1285-1294, 2009.

24. Zhang XH, Chen L, Wang HL and Gao J: Methodological study of determination of rat pulmonary artery pressure. J Chin Med Univ 33: 388-389, 2004 (in Chinese).

25. Wang HM, Wang Y, Liu M, Bai Y, Zhang XH and Wang HL: Fluoxetine inhibits monocrotaline-induced pulmonary arterial remodeling involved in inhibition of RhoA-Rho kinase and Akt signalling pathways in rats. Can J Physiol Pharmacol 90: $1506-1515,2012$

26. Herve P, Launay JM, Scrobohaci ML, et al: Increased plasma serotonin in primary pulmonary hypertension. Am J Med 99 249-254, 1995

27. Hironaka E, Hongo M, Sakai A, et al: Serotonin receptor antagonist inhibits monocrotaline-induced pulmonary hypertension and prolongs survival in rats. Cardiovasc Res 60: 692-699, 2003

28. Morecroft I, White K, Caruso P, et al: Gene therapy by targeted adenovirus-mediated knockdown of pulmonary endothelia Tph1 attenuates hypoxia-induced pulmonary hypertension. Mol Ther 20: 1516-1528, 2012.

29. Fligny C, Fromes Y, Bonnin P, et al: Maternal serotonin influences cardiac function in adult offspring. FASEB J 22: 2340-2349, 2008.

30. MacLean MR and Dempsie Y: Serotonin and pulmonary hypertension-from bench to bedside? Curr Opin Pharmacol 9: 281-286, 2009.

31. Walther DJ, Peter JU, Bashammakh S, Hortnaql H, Voits M, Fink H and Bader M: Synthesis of serotonin by a second tryptophan hydroxylase isoform. Science 299: 76, 2003.

32. Valzelli L, Bernasconi S and Dalessandro M: Time-courses of p-CPA-induced depletion of brain serotonin and muricidal aggression in the rat. Pharmacol Res Commun 15: 387-395, 1983.

33. Ghia JE, Li N, Wang H, et al: Serotonin has a key role in pathogenesis of experimental colitis. Gastroenterology 137: 1649-1660, 2009.

34. Moreau AW, Amar M, Callebert J and Fossier P: Serotonergic modulation of LTP at excitatory and inhibitory synapses in the developing rat visual cortex. Neuroscience 238: 148-158, 2013.

35. Nakadate K, Imamura K and Watanabe Y: C-fos activity mapping reveals differential effects of noradrenaline and serotonin depletion on the regulation of ocular dominance plasticity in rats. Neuroscience 235: 1-9, 2013
36. Song D, Wang HL, Wang S and Zhang XH: 5-Hydroxytryptamineinduced proliferation of pulmonary artery smooth muscle cells are extracellular signal-regulated kinase pathway dependent. Acta Pharmacol Sin 26: 563-567, 2005.

37. Zhai FG, Zhang XH and Wang HL: Fluoxetine protects against monocrotaline-induced pulmonary arterial hypertension: potential roles of induction of apoptosis and upregulation of kv1.5 channels in rats. Clin Exp Pharmacol Physiol 36: 850-856, 2009.

38. Rattray M, Baldessari S, Gobbi M, Mennini T, Samanin R and Bendotti $\mathrm{C}$ : p-Chlorophenylalanine changes serotonin transporter mRNA levels and expression of the gene product. J Neurochem 67: 463-472, 1996.

39. Chelladurai P, Seeger W and Pullamsetti SS: Matrix metalloproteinases and their inhibitors in pulmonary hypertension. Eur Respir J 40: 766-782, 2012.

40. Okada M, Kikuzuki R, Harada T, Hori Y, Yamawaki H and Hara Y: Captopril attenuates matrix metalloproteinase-2 and -9 in monocrotaline-induced right ventricular hypertrophy in rats. J Pharmacol Sci 108: 487-494, 2008.

41. Karthikeyan VJ, Lane DA, Beevers DG, Lip GY and Blann AD: Matrix metalloproteinases and their tissue inhibitors in hypertension-related pregnancy complications. J Hum Hypertens 27: 72-78, 2013.

42. Wang HL: The serotonin receptor and transporter are potential therapeutic targets for pulmonary hypertension. Curr Opin Investig Drugs 5: 963-966, 2004.

43. Shum JK, Melendez JA and Jeffrey JJ: Serotonin-induced MMP-13 production is mediated via phospholipase $\mathrm{C}$, protein kinase C, and ERK1/2 in rat uterine smooth muscle cells. J Biol Chem 277: 42830-42840, 2002.

44. Witzenrath M, Ahrens B, Kube SM, et al: Allergic lung inflammation induces pulmonary vascular hyperresponsiveness. Eur Respir J 28: 370-377, 2006.

45. Hassoun PM, Mouthon L, Barbera JA, et al: Inflammation, growth factors, and pulmonary vascular remodeling. J Am Coll Cardiol 54 (Suppl 1): S10-S19, 2009.

46. Mikulski Z, Zaslona Z, Cakarova L, et al: Serotonin activates murine alveolar macrophages through 5-HT2C receptors. Am J Physiol Lung Cell Mol Physiol 299: L272-L280, 2010.

47. Lima C, Souza VM, Soares AL, Macedo MS, Tavares-de-Lima W and Vargaftig BB: Interference of methysergide, a specific 5-hydroxytryptamine receptor antagonist, with airway chronic allergic inflammation and remodeling in a murine model of asthma. Clin Exp Allergy 37: 723-734, 2007.

48. Kushnir-Sukhov NM, Gilfillan AM, Coleman JW, Brown JM, Bruening S, Toth M and Metcalfe DD: 5-hydroxytryptamine induces mast cell adhesion and migration. J Immunol 177: 6422-6432, 2006.

49. Lawrie A, Waterman E, Southwood M, et al: Evidence of a role for osteoprotegerin in the pathogenesis of pulmonary arterial hypertension. Am J Pathol 172: 256-264, 2008.

50. Wilkins MR: Pulmonary hypertension: the science behind the disease spectrum. Eur Respir Rev 21: 19-26, 2012. 